\title{
Severity of amnesia and the effectiveness of reactivation treatment: Evidence for a retrieval process
}

\author{
DAVID C. RICCIO, CHARLES F. MACTUTUS, CHARLES F. HINDERLITER, \\ and KEVAN McCUTCHEON \\ Kent State University, Kent, Ohio 44242
}

\begin{abstract}
Reactivation of memory following retrograde amnesia treatment may be based on additional learning (storage model) or on gaining access to previously unavailable information (retrieval model). If further learning at reactivation summates with the residual memory, then the effectiveness of reactivation treatment should be inversely related to the degree of amnesia. The present experiment addressed this issue. Severity of retrograde amnesia was manipulated in adult rats by varying the delay $(.5,5$, or $10 \mathrm{~min})$ between punishment training and amnestic treatment (hypothermia). Prior to testing $24 \mathrm{~h}$ later, one half of the subjects received reactivation treatment (recooling). Passive avoidance latencies from the nonrecooled subjects showed the typical temporal gradient of amnesia. Recooling significantly improved retention in the strong amnesia group $(.5 \mathrm{~min})$, marginally improved retention in the moderate amnesia group, and failed to improve retention in the weak amnesia group. Controls for systemic stress demonstrated that the reactivation effect was not a performance artifact. In addition, test scores from a trained-only group were shown to reliably exceed the reactivation scores, suggesting that the magnitude of reactivation was not constrained by either functional or arbitrary ceiling limits. These findings were interpreted as consistent with a recently proposed "contextual cues" model as well as other retrieval-oriented interpretations of amnesia.
\end{abstract}

Experimentally induced retrograde amnesia is a well-documented empirical phenomenon which continues to attract the interest of many researchers in the area of memory. A variety of agents have been shown to produce the characteristic time-dependent memory loss in which the degree of amnesia diminishes as a function of the interval between training and amnestic treatment (Gibbs \& Mark, 1973; McGaugh \& Herz, 1972; Spear, 1978). There is substantial agreement that the observed response deficit represents memory processes rather than the effects of punishment or other performance artifacts. Thus, in the widely employed passive avoidance paradigm, subjects display amnesia by returning to the distinctive area or stimuli that were in close temporal contiguity both to footshock and the amnestic treatment. The severity of retention loss is considered to be a direct function of the rapidity with which animals reenter the shock chamber.

But consensus that amnestic treatments disrupt memorial processes has not been paralleled by agreement on the mechanisms involved. Although distinctions have become blurred in recent years (Lewis,

This investigation was supported in part by the NSF (Grant GB41488) and NIMH (Grant MH30223-01). Charles Hinderliter's present address is Psychology Department, Furman University, Greenville, South Carolina 29613. Requests for reprints should be sent to David C. Riccio, Psychology Department, Kent State University, Kent, Ohio 44242.
1976), two broad classes of interpretation can be discerned. One set of explanations focuses on some form of storage failure or disruption of the target memory; alternative models emphasize the role of retrieval deficits to account for the amnesia. Thus, the time-dependent gradient of amnesia was initially interpreted as evidence that a period of consolidation following the training episode was required for adequate formation of long-term memory (Duncan, 1949; Glickman, 1961; McGaugh, 1966). As a result of this presumed consolidation process, the memory trace was thought to become decreasingly vulnerable to traumatic insult to the central nervous system produced by electroconvulsive shock and other amnesic agents. This interpretation of a trace undergoing stabilization, and the implication that retention loss reflected disrupted storage of the unconsolidated memory trace, has had considerable appeal and is compatible with a number of experimental findings. In recent years, however, several classes of findings have posed a major challenge to the storagefailure model (Lewis, 1976); prominent among these approaches are studies demonstrating recovery of the target memory (e.g., Miller \& Springer, 1973). Although it now seems doubtful that purely spontaneous recovery of memory occurs following treatment with amnestic agents such as ECS or hypothermia (Miller \& Springer, 1973; Riccio \& Stikes, 1969), several investigators have reported that administration of a 
reminder treatment, such as footshock delivered in a apparatus distinctly different from that used in training ("noncontingent footshock"), can reactivate memory in previously amnestic subjects (e.g., Koppenaal, Jagoda, \& Cruce, 1967; Lewis, Misanin, \& Miller, 1968; Miller \& Springer, 1972; Quartermain, McEwen, \& Azmitia, 1970; Schneider, Tyler, \& Jinich, 1974). On the assumption that the memory must have been available in storage in order for the reminder to be effective, these findings have been taken as evidence that amnesia represents a retrieval dificit (Miller \& Springer, 1973, 1974).

While the reactivation phenomenon appears to offer substantial strength to an interpretation of amnesia as a problem of retrievability, such an inference has not gone unchallenged. Since amnesia is often incomplete, it has been argued that reminder treatments merely build upon this residual memory (Cherkin, 1972; Gold \& King, 1974). Thus, the reminder is seen as a further training trial which, through a process akin to stimulus generalization, summates with the weak memory trace left by the amnestic treatment to produce an above-threshold memory. Indirect support for this storage reinterpretation is provided by evidence that when an original target memory of low strength is deliberately established by weak training e.g., mild footshock, the reminder treatment can increase the strength of the response at testing (Gold, Haycock, Macri, \& McGaugh, 1973). Clearly, the enhanced performance must be derived from the interpolated treatment rather than the original memory.

The present study was designed to bear on these conflicting interpretations of retrograde amnesia. Our general strategy involved examining the relationship between the severity of amnesia and the effectiveness of a reactivation treatment. If, as a storage viewpoint suggests, the similarity of training and reactivation events permits the latter to strengthen a partial memory, then induced recovery should be greater as the amount of residual memory increases. In contrast, a retrieval model (e.g., Hinderliter, Webster, \& Riccio, 1975) can predict the opposite, seemingly paradoxical, outcome: Reactivation should be maximal when memory is weakest, i.e., in the condition where amnesia is most severe.

Using similar reasoning, DeVietti and Bucy (1975) examined the effectiveness of reactivation following ECS treatment. The strength of ECS-induced amnesia in a lick suppression paradigm was varied by manipulating the interval between the training/ECS administration and the subsequent reminder episode. The reminder, a weak footshock $1 \mathrm{~h}$ after a test trial, produced memory recovery under the strong amnesia condition, but not when the amnesia was weak. The present experiment differed in a number of ways from the DeVietti and Bucy (1975) study. The task consisted of punishment for a cross-through response, testing involved passive avoidance, and hypothermia served as the amnestic agent and reactivation treatment. More importantly, in order to obtain memory of different strengths, we took advantage of the delay of treatment gradient. This procedure also has the virtue of direct relevancy to the issue of conditions affecting induced recovery of memory. Hypothermia was employed as the amnesic agent because previous research showed not only that it is an effective method of producing amnesia (Beitel \& Porter, 1968; Riccio, Hodges, \& Randall, 1968), but also that recooling provides a powerful reactivation treatment for the subjects (Hinderliter et al., 1975; Mactutus \& Riccio, 1978).

\section{METHOD}

\section{Subjects}

Sixty-four adult Holtzman albino male rats (282-470 g) served as subjects. The rats were housed individually in cages in a colony maintained at $20^{\circ}-22^{\circ} \mathrm{C}$ on a 16-h-light/8-h-dark cycle. Food and water were available ad lib throughout the study.

\section{Apparatus}

The training apparatus was a Plexiglas and aluminum passive avoidance chamber $(45.5 \times 17.5 \times 23.5 \mathrm{~cm})$ divided into two equal-sized compartments by a partition. A door could be raised or lowered to control passage through a $6.5 \times 9.0 \mathrm{~cm}$ opening to either compartment, one having white walls with a clear Plexiglas lid, the other having both black walls and a black lid. The flooring in both compartments consisted of $20-\mathrm{cm}$ grids spaced $1.0 \mathrm{~cm}$ apart. A $1-\mathrm{sec} 150-\mathrm{V}$ shock from a matched impedance ac shock source (Campbell \& Teghtsoonian, 1958) could be delivered through a Foringer Model SC-901 scrambler to the grid floors of the black compartment. A $15-\mathrm{W}$ light bulb suspended $30 \mathrm{~cm}$ above the white compartment was the only light in the experimental room. Standard electromechanical equipment was used to measure each animal's cross-through latencies to the nearest $.1 \mathrm{sec}$. In a separate room, an unpainted plywood box $(18.5 \times 15.5 \times 20.0 \mathrm{~cm})$ with a clear Plexiglas lid was used to administer noncontingent footshock through an identical electrical system.

Hypothermia was produced using a Model 1095 Forma Temp Jr. water bath and circulator which was maintained at $3^{\circ}-5^{\circ} \mathrm{C}$. Subjects were restrained in wire cloth cylinders while immersed. A rectal probe inserted approximately $3.2 \mathrm{~cm}$ into the rat's anus measured body temperature on a Yellow Springs Tele-thermometer, Model 43TD.

\section{Procedure}

The general plan of the experiment was to present the amnestic treatment $.5,5$, or $10 \mathrm{~min}$ after training. Half of the rats from each group were given a reminder treatment $2 \mathrm{~h}$ before a retention test.

More specifically, 4 days before training, the rats were weighed, ear punched, and individually caged. Each animal was handled for 5 min on each of the following 3 days. Training involved placing each rat in the white side of the passive avoidance apparatus facing away from the door. After $10 \mathrm{sec}$, the door was raised and the latency to place all four feet into the black chamber was recorded to the nearest $.1 \mathrm{sec}$. Contingent upon the crossthrough response, rats received an inescapable $1-\mathrm{sec} 150-\mathrm{V}$ scrambled footshock. Hypothermia treatment involved restraining the animals in wire-mesh cylinders and partially immersing them in $3^{\circ}-5^{\circ} \mathrm{C}$ water until rectal temperature reached $21^{\circ} \mathrm{C}$. The animals were subsequently wiped with paper towels to remove excess moisture before being returned to their home cages. 
Twenty-two hours after the end of hypothermia treatment, one-half of the animals in each treatment condition received a recooling treatment, differing from the original treatment only in that body temperatures were lowered to a criterion of $25^{\circ} \mathrm{C}$. The passive avoidance retention test was then administered when body temperature increased to $29^{\circ}-31^{\circ} \mathrm{C}$, which was approximately $24 \mathrm{~h}$ after training. For those subjects not recooled, the test was given $24 \mathrm{~h}$ after training. The testing procedure was identical to training except that no shock was administered. Latency to leave the safe compartment provided the index of retention; animals not crossing within $1 \mathrm{~h}$ were assigned latencies of $3,600 \mathrm{sec}$.

To evaluate the effect of shock and/or repeated hypothermia treatments on response latency, a group of 16 rats with no exposure to the passive avoidance apparatus received a 1-sec, 150-V inescapable shock $10 \mathrm{sec}$ after being placed in an unpainted plywood box. These noncontingent footshock controls then received hypothermia at the .5 -min delay interval. Prior to testing $24 \mathrm{~h}$ later, one half of the group received the recooling treatment, the other half received no interpolated treatment.

Subsequent to collection of data in the main experiment, nine animals were run as a baseline retention control condition. These subjects simply received passive avoidance training followed by the retention test $24 \mathrm{~h}$ later. While there is ample evidence that passive avoidance is well retained over $24 \mathrm{~h}$ or longer in adult rats (Ader, Weijnen, \& Moleman, 1972; Schulenburg, Riccio, \& Stikes, 1971), our intent was to demonstrate that the response strength generated by conditioning per se would be at, or near, the arbitrarily selected ceiling of $60 \mathrm{~min}$.

\section{RESULTS}

As expected, there were no statistically significant differences among the groups in initial response latencies prior to punishment $(\mathrm{F}<1, \mathrm{p}>.5)$. Subsequent retention test latencies for the groups are presented in Figure 1. Heterogeneity of error variance of the test data precluded parametric analysis. Nonparametric analyses (two-tailed) confirmed the temporal gradient of amnesia in nonrecooled animals

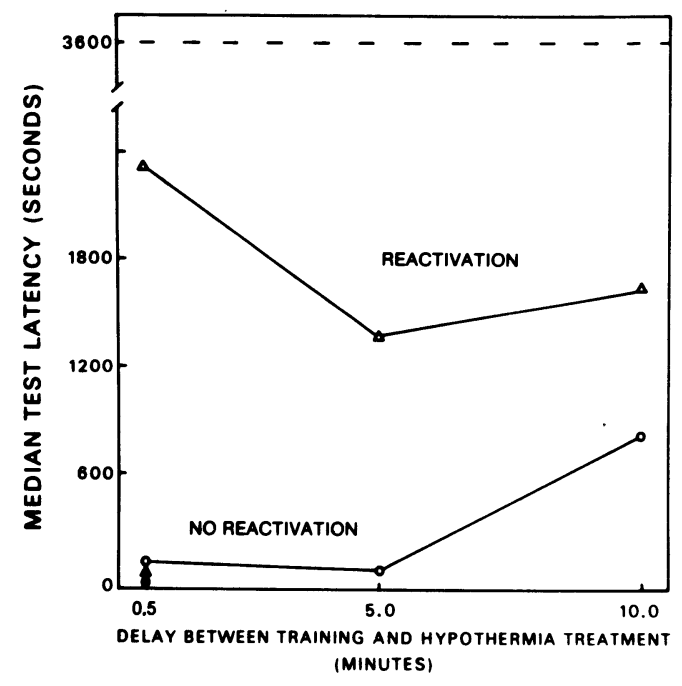

Figure 1. Median latency on test trial with or without reactivation as a function of the delay between training and amnestic treatment. Scores of performance control groups receiving noncontingent footshock and hypothermia with $(\Delta)$ or without $(\bullet)$ reactivation are also shown. The dashed line represents the median score of subjects given punishment training only.
$(\mathrm{H}=6.87, \mathrm{p} \leqslant .05)$. That the memory deficit was nearly complete in the .5- and 5-min delay groups is suggested by the fact that their scores were comparable to those of the untrained controls ( $p s>$ .10). It is also clear from the figure that reactivation treatment produced a diminishing increment in performance as a function of the delay interval. As Figure 1 suggests, the absolute level of response latencies was similar among the recooled groups $(\mathrm{H}<1, \mathrm{p}>.5)$. However, relative to the respective nonrecooled groups, reactivation treatment significantly improved retention in the strong amnesia condition $(p \leqslant .05)$, marginally improved retention in the moderate amnesia group $(p \leqslant .08)$, and failed to improve retention in the weak amnesia condition $(\mathrm{p}>.70)$.

The smaller gain in the reactivated groups at the longer intervals is not readily dismissed as an artifact of ceiling limitations. Only 5 of 16 scores in the two longer delays reached the 60-min cutoff. Moreover, conservatively considering the $10-\mathrm{min}$ delay group without recooling (median of $817 \mathrm{sec}$ ) as an estimate of residual memory prior to reactivation would still leave a maximum potential gain of about 2,800 sec, an amount well above the obtained increment. A related concern was whether the arbitrary ceiling might, in fact, exceed the maximum memory strength supported by conditioning in this situation. Of the nine rats in the passive avoidance retention condition, seven showed maximum latencies. It appears then that the upper limit was functionally obtainable. In addition, despite the compression effect from the large proportion of indeterminant scores in this control group, their median latency $(3,600 \mathrm{sec})$ was marginally longer than that for the pooled reactivation groups $(\mathrm{Z}=2.16, \mathrm{p} \leqslant .03)$. Taken together, these results suggest that the magnitude of the reactivation effect was not appreciably constrained by either arbitrary or functional upper limits of the response scale.

\section{DISCUSSION}

These findings agree with previous research in demonstrating that amnesia induced by hypothermia can be alleviated by recooling subjects prior to testing (Hinderliter et al., 1975; Mactutus \& Riccio, 1978). The reactivation effect is not attributable to general systemic stress or motor debilitation, as the untrained controls receiving a comparable series of events (e.g., noncontingent footshock, hypothermia, recooling) emitted the cross-through response with very brief latencies. More importantly, these data indicate that the magnitude of the reactivation effect does not increase in parallel with increases in residual memory which result from lengthening the interval between training and amnestic treatment. Rather, the relative effectiveness of the reminder is greatest where memory loss is most pronounced. 
The inverse relationship between severity of amnesia and the effectiveness of reactivation is in agreement with the findings reported by DeVietti and Bucy (1975), and appears consistent with retrievaloriented interpretations of memory loss. We have described previously a "contextual cues" retrieval model of amnesia which emphasizes the importance of matching immediate posttrial stimuli with those present at testing (Hinderliter et al., 1975). This contextual cues notion, in common with one form of a state-dependency analysis (Thompson \& Grossman, 1972; Thompson \& Neely, 1970), proposes that processing of information persists after termination of training. However, the target memory is assumed to become linked with, or embedded in, the constellation of cues associated with the amnestic treatment rather than destroyed. Retention loss in amnesia would reflect the mismatch between encoding and retrieval conditions (cf. Tulving, 1974).

Of central importance here is the notion that the temporal gradient occurs because the target memory is less apt to be encoded with cues of the amnestic state as the training to treatment interval lengthens. Conversely, if the training episode is embedded in hypothermia-related stimuli, as is presumed to be the case with the 0.5 -min delay, then recooling should constitute a potent retrieval device. With longer delays, posttrial processing is more or less completed before the amnestic agent; hence, the target memory is both relatively intact and less susceptible to reactivation effects of the recooling.

While other retrieval models could also undoubtedly account for our findings, in our view it is difficult to reconcile these findings with a storagefailure model of amnesia. If the reactivation effect depends upon additional learning during the reminder episode, then it is puzzling that recovery from amnesia was more complete under the condition where the memory deficit was most profound. Moreover, it should be noted that the environmental cues present during deep body cooling and the nature of the hypothermia itself are appreciably different from the conditioned and unconditioned stimuli of the training trial. Thus, as with pharmacological manipulations (Quartermain \& Botwinick, 1975), memory recovery is induced under circumstances where further learning seems highly improbable. In this respect, such reactivation paradigms appear to offer advantages over the use of noncontingent footshock to reactivate memory based on shock as the UCS. We would agree that the effects of hypothermia may still share certain similarities with the training experience, since the stressful nature of both probably yields partially common internal states. Whatever the merits of the present interpretation, we think the paradigm may prove fruitful in distinguishing between memory recovery based upon additional learn- ing during reactivation treatment or upon the presence of critical retrieval cues.

\section{REFERENCES}

Ader, R., Weijnen, J. A. W. M., \& Moleman, P. Retention of passive avoidance response as a function of the intensity and duration of electric shock. Psychonomic Science, 1972, 26, 125-128.

Beitel, R. E., \& Porter, P. B. Deficits in short- and long-term retention and impairments in learning induced by severe hypothermia in mice. Journal of Comparative and Physiological Psychology, 1968, 66, 53-59.

Campbell, B. A., \& Teghtsoonian, R. Electrical and behavioral effects of different types of shock stimuli on the rat. Journal of Comparative and Physiological Psychology, 1958, 51, 185-192.

Cherkin, A. Retrograde amnesia in the chick: Resistance to the reminder effect. Physiology \& Behavior, 1972, 8, 949-955.

DeVietTi, T. L., \& BuCY, C. E. Recovery of memory after reminder: Evidence for two forms of retrieval deficit induced by ECS. Physiological Psychology, 1975, 3, 19-25.

Duncan, C. P. The retroactive effect of electroshock on learning. Journal of Comparative and Physiological Psychology, 1949, 42, $32-44$.

GIBBS, M. E., \& MARK, R. F. Inhibition of memory formation. New York: Plenum, 1973.

Glickman, S. E. Perseverative neural processes and consolidation of the memory trace. Psychological Bulletin, 1961, 58, 218-233.

Gold, P. E., Haycock, J. W., Maric, J., \& McGaugh, J. L. Retrograde amnesia and the "reminder effect": An alternative interpretation. Science, 1973, 180, 1199-1201.

Gold, P. E., \& King, R. A. Retrograde amnesia: Storage failure versus retrieval failure. Psychological Review, 1974, 81, 465-469.

Hinderliter, C. F., Webster, T., \& Riccio, D. C. Amnesia induced by hypothermia as a function of treatment-test interval and recooling in rats. Animal Learning \& Behavior, 1975, 3, 257-263.

KoppenaAl, R. J., Jagoda, E., \& Cruce, J. A. F. Recovery from ECS-produced amnesia following a reminder. Psychonomic Science, 1967, 9, 293-294.

LEwIS, D. J. A cognitive approach to experimental amnesia. American Journal of Psychology, 1976, 89, 51-80.

Lewis, D. J., Misanin, J. R., \& Miller, R. R. Recovery of memory following amnesia. Nature, 1968, 220, 704-705.

Mactutus, C. F., \& Riccio, D. C. Hypothermia-induced retrograde amnesia: Role of body temperature in memory retrieval. Physiological Psychology, 1978, 6, 18-22.

McGaugh, J. L. Time-dependent processes in memory storage. Science, 1966, 153, 1351-1358.

McGaugh, J. L., \& Herz, M. J. Memory consolidation. San Francisco: Albion, 1972.

MilleR, R. R., \& SPRingeR, A. D. Induced recovery of memory in rats following electroconvulsive shock. Physiology \& Behavior, 1972, 8, 645-651.

Miller, R. R., \& Springer, A. D. Amnesia, consolidation, and retrieval. Psychological Review, 1973, 80, 69-79.

MilleR, R. R., \& SPRINGer, A. D. Implications of recovery from experimental amnesia. Psychological Review, 1974, 81, 470-473.

Quartermain, D., \& Botwinick, C. Y. Role of the biogenic amines in the reversal of cycloheximide-induced amnesia. Journal of Comparative and Physiological Psychology, 1975, 88, 386-401.

Quartermain, D., McEwen, B. S., \& Azmitia, E. C., JR. Amnesia produced by electroconvulsive shock or cycloheximide: Conditions for recovery. Science, 1970, 169, 683-686. 
Riccio, D. C., Hodges, L. A., \& Randall, P. K. Retrograde amnesia produced by hypothermia in rats. Journal of Comparative and Physiological Psychology, 1968, 66, 618-622.

Riccio, D. C., \& Stikes, E. R. Persistent but modifiable retrograde amnesia produced by hypothermia. Physiology \& Behavior, 1969, 4, 649-652.

SChNeIDER, A. M., TyleR, J., \& Jinich, D. Recovery from retrograde amnesia: A learning process. Science, 1974, 184, 87-88.

Schulenburg, C. J., Riccio, D. C., \& Stikes, E. R. Acquisition and retention of a passive-avoidance response as a function of age in rats. Journal of Comparative and Physiological Psychology, 1971, 74, 75-83.

SPEAR, N. E. The processing of memories: Forgetting and retention. Hillsdale, N.J: Erlbaum, 1978.
Thompson, C. I., \& Grossman, L. B. Loss and recovery of longterm memories after ECS in rats: Evidence for state-dependent recall. Journal of Comparative and Physiological Psychology, 1972, 78, 248-254.

Trompson, C. I., \& Neeley, J. E. Dissociated learning in rats produced by electroconvulsive shock. Physiology \& Behavior, $1970,5,783-786$.

Tulving, E. Cue-dependent forgetting. American Scientist, 1974, 62, 74-82.

(Received for publication May 22, 1978; revision accepted October 23,1978 .) 